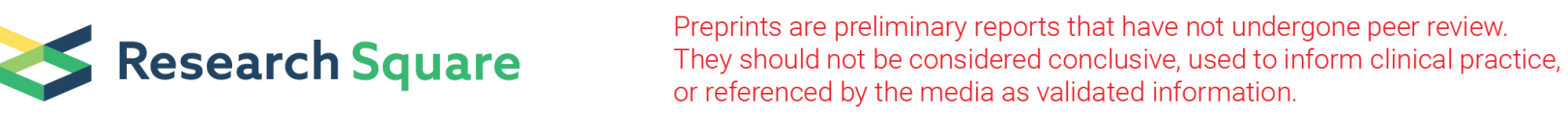

\title{
Adaption of Hunter's Method and generation of synthetic series from disaggregation of flow time series, comparative analysis with existing models
}

\section{Christian Paúl Mera}

Universidad Técnica Particular de Loja: Universidad Tecnica Particular de Loja

Holger Benavides-Muñoz ( $\nabla$ holgerbenavides@gmail.com )

Universidad Técnica Particular de Loja https://orcid.org/0000-0001-7075-0905

\section{Research Article}

Keywords: Hunter, stochastic, flowrate, probability, water consumption, domestic water

Posted Date: March 15th, 2021

DOl: https://doi.org/10.21203/rs.3.rs-317546/v1

License: (c) (i) This work is licensed under a Creative Commons Attribution 4.0 International License.

Read Full License 
1 Adaption of Hunter's Method and generation of synthetic series from

2 disaggregation of flow time series, comparative analysis with existing models.

4

5 Master's Program in Water Resources, Universidad Técnica Particular de Loja (UTPL), 6

${ }^{1}$ Christian Paúl Mera and ${ }^{2}$ Holger Benavides-Muñoz

San Cayetano Alto s/n; 1101608 Loja, Ecuador; cpmera@utpl.edu.ec

Professor of the Water Resources Departmental Section, Universidad Técnica Particular de Loja (UTPL), San Cayetano Alto, Loja-Ecuador; hmbenavides@utpl.edu.ec

Correspondence: hmbenavides@utpl.edu.ec

\section{Abstract}

12 Water demand is a non-deterministic variable; current normative deliver different flow rates than might occur. Adaptations have been developed in different countries mainly for Hunter's method. The Hydro-Sanitary Standard 'Norma Hidrosanitaria Ecuatoriana' (NHE) 2011 in Ecuador proposes a demand calculation through a modification to the Norme Francaise NF P 40-202. This study proposes an adaptation to the Hunter's Method using a binomial probability function, based on the disaggregation of time series of pressure and flow, during 62 consumption days, in different water meters, in academic facilities in Loja, Ecuador. Flow curves were developed based on consumption units, which gave very assertive values in relation to the maximum recorded flow rates. Also, in order to approach different estimation methods and since water consumption over time follows a Poisson distribution, synthetic series were generated using the Neyman Scott Rectangular Pulse Model (NSRPM), as this is the one that most adheres to the actual user behavior. Maximum flow rate was also determined with Water Demand Calculator (WDC) and NHE 2011 for comparison with NSRP and research results. Current research 
is an exploratory approach, has a methodological value for subsequent studies. Proposed Hunter's Method adaptation can provide an accurate flow estimation. Flows obtained with NHE 2011 method were closed to observed only in small facilities. NSRPM method showed an exactness high level, with only a $1.1 \%$ percentage difference compared to the measured one.

Keywords: Hunter, stochastic, flowrate, probability, water consumption, domestic water.

\section{Introduction}

An internal water distribution network, properly sized, according to the demands of pressure and flow, proposes a rational and sustainable use of water, inexcusable in a global water stress scenario (Wong and Mui 2006; Blokker et al. 2010; Mazumdar et al. 2013; Gargano et al. 2016). Trends in demands and water consumption can be deterministic or stochastic. Deterministic demands, such as industrial demands, can be estimated based on actual operating conditions, while stochastic demands respond to an ever-changing consumption pattern, such as residential (García et al. 2004; Buchberger and Li 2007; Blokker et al. 2010; Gargano et al. 2016).

The hydro-sanitary networks are usually designed considering different flow demands than the actual ones, affecting the performance of the network (Castro et al. 2006a; Cortés 2008; Mazumdar et al. 2013). The Simultaneity Factor (SF) is considered an empirical method, since its base is experience, it is considered optimal for small networks. The Hunter's Method (HM) is supported by the probabilistic analysis of maximum consumption periods (Soriano and Pancorbo 2012).

The SF was first adopted in the French Standard NFP 41-201 (Soriano and Pancorbo 2012), there are variations of it for different countries, such as the Spanish Standards NTEF and NTEC, mainly (Soriano and Pancorbo 2012). In Ecuador, the current NHE 
Hydro-Sanitary Standard proposes a determination of the maximum probable flow ( $Q m p$ ) through a modification to the French Standard NFP 41-204 (Miduvi 2011). The HM, has an adaptation of the Colombian standard NTC 1500 (Soriano and Pancorbo 2012), which considers variations around the factors of consumer units, generating a lower demand than original Hunter (Castro et al. 2006a, b; Omaghomi and Buchberger 2014; INCOTEC 2017).

According to Hunter (1940), who developed a probabilistic model for Qmp determination, the probability of simultaneous consumption of several sanitary appliances ( $s a$ ) is low, so the $Q m p$ should not be a simple sum of $s a$ consumption. To determine the $Q m p$, the HM assigns dimensionless capacity factors to different sanitary devices with a maximum frequency of use and assumed duration, generating a corresponding maximum probable demand (Cortés 2008; Mazumdar et al. 2013; Omaghomi and Buchberger 2014).

Hunter (1940), indicated that a system works satisfactorily whenever a certain number of $m$ devices out of a total $n$ operate simultaneously $99 \%$ of the time. In other words, Hunter used the 99th percentile as the standard design margin to estimate maximum demand (Mazumdar et al. 2013; Buchberger et al. 2017).

Hunter introduced the concept of supply units, or capacity factors, for the various $s a$, to measure the incidence in a hydraulic system (Cortés 2008). With the supply units, Hunter generated consumption curves, in a single design curve, this curve is known as Hunter Curve (Mazumdar et al. 2013). Both HM and SF consider demands according to the $s a$ available at the time they were developed, being currently more efficient and with lower flow rates (Cortés 2008; Manco et al. 2012; Mazumdar et al. 2013; Buchberger et al. 2017). 
In addition, SF and HM were developed considering consumption habits from different eras (Cortés 2008; Buchberger et al. 2017). The daily cycle in water consumption has a close relationship with the weather factors that occur in a region (García et al. 2004; Polebitski and Palmer 2010; Ghimire et al. 2016), so the demand that can be generated at the domestic level, can vary between regions.

Current $s a$ are manufactured with a trend of low consumption, this being a factor that must be considered for the updating of methods of sanitary hydraulic design (Cortés 2008; Manco et al. 2012; Soriano and Pancorbo 2012; Mazumdar et al. 2013; Buchberger et al. 2017; Omaghomi et al. 2020).

Alcocer-Yamanaka and Tzatchkov (2009); following the methodology originally developed by Alvisi et al. (2003); considered that residential consumption is a stochastic process that follows a Poisson distribution under rectangular pulses of a certain intensity, duration and frequency, and used the NSRPM for the generation of synthetic series from theoretical moments (calculated) and observed moments (field data), using nonlinear optimization. They worked with a database generated from field measurements in nine houses in the same area in Culiacán, Sinaloa.

Buchberger et al. (2017), were convened by the International Association of Plumbing and Mechanical Officers (IAPMO) and the American Society of Plumbing Engineers (ASPE), to review the methodology and adequately estimate local demands. The research consisted of developing a probability model capable of predicting the maximum demand for domestic water, resulting in the Water Demand Calculator (WDC) model. For that, they used a database of measurements taken between 1996 and 2011 in more than 1000 single-family homes in the United States. An average of 11 days of monitoring per household, 2.72 residents per household and 831.4 events per household were achieved. 
Gargano et al. (2016), on the basis that residential consumption is random in nature, they presented a stochastic model for their daily characterization. They generated a mixed probabilistic distribution, combining a random discrete variable distribution fusion and a continuous random variable. Their model was generated based on records from three real networks. The synthetic series generated demonstrated the efficiency of the stochastic model for residential water demand.

In Bogota, Colombia, Castro et al. (2006a), studied and evaluated existing methods for determining maximum flows in relation to actual maximum flow capacity. They demonstrated that existing methods provide lower flows than the actual flow rates. Castro et al. (2006b), submitted a modification to Hunter's Method, alluding that, due to its probabilistic support in duration and frequency of consumption, $Q m p$ assertive values can be determined according to a region.

In Mexico City, Mexico, Cortés (2008), an update of Hunter's Method for hydraulic installations in buildings was presented, performing a wide field data collection such as the duration, frequency and volumetric expenditure of each $s a$, reaching to determine different design curves, for buildings of different uses.

Mazumdar et al. (2013), in India, made a modification to the Hunter curve incorporating the low flow rates of modern accessories, and decreasing the level of confidence in the binomial probability function as raised by Hunter (1940).

Currently, in Ecuador, there is no research that validates the methodology of the NHE Hydro-Sanitary Standard, in relation to the maximum instantaneous flow rates measured. Also, there's no proposals linked to the probabilistic basis in relation to Hunter's method. Given this absence of methodological evaluations, research is necessary to evaluate Hunter's Method and make an adaptation. 
123 This study adapts Hunter's method to local conditions, based on the temporal 124 disaggregation of frequency, duration and expenditure variables in capacity studies 125 carried out in various educational complexes in the city of Loja, Ecuador. With the generation of consumption curves, this research seeks to provide an exploratory

127 theoretical and methodological sustenance for the design of hydro-sanitary networks in 128 Ecuador. In addition, it seeks to give practical validity to the current norm. Synthetic series simulations were generated using the NSRPM model, following the methodology set out by Alcocer (2007) and using the model developed by Camici et al. (2011), the maximum probable flow was also determined with the WDC model developed by Buchberger et al. (2017).

\section{Methodology}

\subsection{Sites selected for study.}

137 The study was carried out in the city of Loja, Ecuador, in five educational buildings, 138 locating the equipment immediately after the water meter. A water meter with a source pipe of $0.0254 \mathrm{~m} \mathrm{(1")} \mathrm{diameter,} \mathrm{it} \mathrm{records} \mathrm{the} \mathrm{consumption} \mathrm{of} 1514$ people, at the same time it was designated as A water meter. Another water meter with $0.0254 \mathrm{~m}(1 ")$ source pipe detects the consumption of 817 people, this is named B water meter. The water meter with source pipe of $0.0200 \mathrm{~m}(3 / 4 ")$ diameter measures the water consumption of 312 people, which is named $\mathrm{C}$ water meter. Another water meter with source pipe of 0.0125 $\mathrm{m}(1 / 2 ")$ diameter records the consumption of 360 people, this is named $\mathrm{D}$ water meter. Finally, a water meter with source pipe of $0.0200 \mathrm{~m}(3 / 4 ")$ detects the consumption of 220 people, this is named $\mathrm{E}$ water meter.

\subsection{Equipment used and monitoring system}


The monitoring node installed after each water meter consisted of a Temperature

Pressure Transducers Model PX1004L1-500AV (Engineering Omega) Pressure Data

A F300. (KOBOLD). The temporal flow and pressure variation were recorded.

\subsubsection{Technical aspects of the equipment used}

Equipment type PX1004L1, have a margin of error of $0.25 \%$ in their pressure register, with a working range of $0.0 \mathrm{KPa}$ to $3447.4 \mathrm{KPa}$ (0psi to $500 \mathrm{psi}$ ) (Engineering Omega). The MIK-5NA50 Flow Meter records flow rates from $0.053 \mathrm{l} / \mathrm{s}$, with an accuracy of $2.00 \%$ (KOBOLD). Pressure data was processed using the OM-PL Series Interface Software Version 2.31x program (Omega Eng).

\subsubsection{Recorded information and monitoring time}

The flow rate record was performed at one-minute intervals, for an average of 12 days for each water meter. Network pressures were recorded in shorter periods, varying from 4 seconds to 1 minute, depending on the memory availability on the computer, in an average of 12 days per pressure data logger.

It was carried out a survey of the existing sanitary hydraulic infrastructure in each studied educational establishment, the number and type of appliances were determined in relation to the water meter from which they are supplied. With data from pressure records and flow records, double-axis daily graphs were generated, representing pressure variation and expenditure per unit of time.

\subsection{Hunter's Method.}

Based on the methodology set out by Cortés (2008), and developed by Mazumdar et al. (2013), a data collection was made for the variables involved in the probabilistic support of the Hunter's Method (1940). The duration of use $(t)$ in seconds, the frequency of use 
173 (i) in seconds, and the maximum consumption period $(h)$ in seconds, also known as the 174 top period; were obtained through the pressure and flow graphs over time.

175 Both the interval between discharges $(i)$ and the duration $(t)$; during the peak period $(h)$; 176 were set as averages in the entire observation period. (Hunter 1940). The adaptation of 177 hunter's method is based on a stochastic simulation with evenly distributed random 178 numbers, as Cortés (2008) explains if $n$ sa exist, used every $i$ seconds, for $t$-seconds, the 179 probability that $r$ amount of $s a$ operate simultaneously can be determined by equations 180 from (1) to (6).

181 1) The $n$ probability of finding the discharge of a sanitary appliance at any time is 182 determined by equation (1) (Cortés 2008):

$$
\mathrm{p}=\frac{\mathrm{t}}{\mathrm{i}}
$$

2) For the $r$ selection, a total of $n$, as combinations of $n$ appliances taken from $r$ at a given moment was estimated by expression (2) (Cortés 2008):

$$
\mathrm{C}_{\mathrm{r}}^{\mathrm{n}}=\frac{\mathrm{n} !}{\mathrm{r} !(\mathrm{n}-\mathrm{r}) !}
$$

185 3) Finally, the probability of $r$ devices working at the same time was determined by 186 equation (3) (Cortés 2008):

$$
P_{r}^{n}=C_{r}^{n} p^{r}(1-p)^{n-r}
$$

The maximum instantaneous flow $Q m$ was determined through equation (4) (Cortés 2008):

$$
Q m=m q
$$

Where $q$ is the volumetric flow per unit of time of a sanitary appliance, $m$ is the design factor, understood as the $r$ value taken from the $n s a$ in simultaneous use, $i$.e. the amount $\mathrm{m}$ of $s a$ that they are discharging during the interval of $t$ seconds immediately preceding the observation time. 
Equation (5) is the mathematical condition used to evaluate the percentage of time in which the appliances are operating simultaneously (known as confidence level), proposed by (Cortés 2008):

$$
\mathrm{p}_{0}{ }^{\mathrm{n}}+\mathrm{p}_{1}{ }^{\mathrm{n}} \ldots+\mathrm{p}_{\mathrm{m}-1}{ }^{\mathrm{n}}+\mathrm{p}_{\mathrm{m}}{ }^{\mathrm{n}} \geq 0.99
$$

From equation (5) can be interpreted that when the sum of probabilities, determined with several $r$ values $P_{r}^{n}$ applied in equation (3) for a random number $n$, is greater than 0.99 , the last value of $r$; for which this condition was given; becomes $m$ and to be applied in equation (4).

To find the capacity factors of the appliances, it was used equation (6) (Cortés 2008):

$$
\frac{f}{f_{i}}=\frac{n_{i}}{n}
$$

Where $f$ is the arbitrary capacity factor assumed for the most energy-intensive furniture; $f_{i}$ is the capacity factor to find, $n$ is the $s a$ number corresponding to $f, n_{i}$ corresponds to the amount of $s a$ different of $n$ which the same probable flow is generated. Capacity factors are arbitrary values that weight and measure the effect of demand (Hunter 1940; Cortés 2008).

Two types of consumption curves have been developed, $i$ ) Probable Flow based on $n$ and ii) Probable Flow depending on appliance or consumption units. For the elaboration of these graphs, it has been started with the determination of $n$ through equation (1). With random values of $n$, different values of $r$ have been evaluated with equations (2) and (3) until the condition (5) is met. Once $m$ values have been determined for corresponding random values of $n$, equation (4) has been applied, with a given flow $q$ for each water meter. Subsequently, consumption factors have been assigned to each piece of appliance, giving a factor of 10 to the most flow generator that is the sink, generalizing a value per weight for each building, assuming a proportional consumption of each $s a$.

\subsection{Water Demand Calculator (WDC)}


217 The WDC was developed by Buchberger et al. (2017), to determine the probable demand 218 for indoor water. WDC chooses between 4 methodologies and 2 topological aspects of 219 consumption (individual and multifamily house). To choose the method, in addition to 220 the topological aspects, the hunter's number is determined using equation (7) (Buchberger 221 et al. 2017):

$$
H(n, p)=\sum_{k=1}^{k} n_{k} p_{k}
$$

222 Where $n_{k}$ is the total of sanitary appliances belonging to the same class $k$, and $p_{k}$ is the probability that a single type $k$ appliance is operating. Equation (7) represents the estimated number of sanitary appliances occupied simultaneously over a peak period.

\subsection{Neyman Scott Rectangular Pulse (NSRPM)}

El NSRPM is a stochastic approach for representing domestic consumption, which can work with different logging intervals, when considering a temporary demand disaggregation. It has been used mainly in the field of hydrology, to generate synthetic series of precipitation, using statistical parameters similar to the observed records, such as the average, variance, and covariance (Camici et al. 2011).

For this study was followed a process of disaggregation, which consisted of data analysis, model formulation, estimation of statistical parameters and validation of the synthetic series (Alcocer-Yamanaka and Tzatchkov 2009). The theoretical and observed moments were determined in the data analysis. The observed moments are used in the minimization of an objective function considering a nonlinear mathematical programming (NLP), obtaining the theoretical moments (Alcocer 2007; Alcocer-Yamanaka and Tzatchkov 2009; Arreguín et al. 2010; Camici et al. 2011; 
239 The analysis interval was set to one minute, as the flow records have that measurement

240 interval. Following the methodology set out by Alcocer (2007), the flow records were

241 assembled into a data series, from which the average time between two events $\lambda^{-1}$, was

242 determined, the average time between each individual pulse and the event source $\beta^{-1}$, the

243 average pulse duration $n^{-1}$, the average intensity (flow) of the pulses $u_{x}$, and the

244 aggregation/disaggregation interval analyzed $h$ (1 minute).

245 The average of the observed moments is given by equation (8) and variance for the

246 observed moments is determined by the expression (9) (Alcocer 2007):

$$
\mathrm{E}\left[\mathrm{Y}_{\mathrm{i}}^{(\mathrm{h})}\right]=\frac{\lambda}{\eta} \mu_{\mathrm{c}} \mu_{\mathrm{x}} \mathrm{h}
$$

247 In equation $08, \mu_{c}$ represents the average value of cells or pulses per event.

$$
\begin{aligned}
\operatorname{Var}\left[\mathrm{Y}_{i}^{(\mathrm{h})}\right] & =\left[\frac{\lambda}{\eta^{3}}\left(\eta \mathrm{h}-1+\mathrm{e}^{-\mathrm{nh}}\right)\right]\left[2 \mu_{\mathrm{c}} \mathrm{E}\left[\mathrm{x}^{2}\right]+\mathrm{E}\left[\mathrm{C}^{2}+\mathrm{C}\right] \mu^{2} \times \frac{\beta^{2}}{\beta^{2}-\eta^{2}}\right] \\
& -\lambda\left(\beta \mathrm{h}-1+\mathrm{e}^{-\beta \mathrm{h}}\right) \mathrm{E}\left[\mathrm{C}^{2}-\mathrm{C}\right] \mu^{2} \mathrm{x}\left[\frac{\beta^{2}}{\beta\left(\beta^{2}+\eta^{2}\right)}\right]
\end{aligned}
$$

248 Equation (9) corresponds to an exponential distribution, so it $E\left[x^{2}\right]$ responds to equation 249 (10) (Alcocer 2007):

$$
\mathrm{E}\left[\mathrm{x}^{2}\right]=2 \mu_{\mathrm{x}}
$$

250 Being $E[C]=\mu_{c}$, we have the equation (11), for a case of type Poisson (Alcocer 2007):

$$
\mathrm{E}\left[\mathrm{C}^{2}+\mathrm{C}\right]=\mu_{c}^{2}-1
$$

251 The covariance calculated from the observed moments is determined by equation (12)

252 (Alcocer 2007): 


$$
\begin{aligned}
\operatorname{Cov}\left[Y_{i}^{(h)}, Y_{i+k}^{(h)}\right] & \\
= & {\left[\frac{\lambda}{\eta^{3}}\left(1-e^{-\eta h}\right)^{2} e^{-\eta(k-1) h}\right]\left[\mu_{c} E\left[X^{2}\right]\right.} \\
& \left.+\frac{1}{2} E\left[C^{2}-C\right] \mu_{X}^{2} \frac{1}{\beta\left(\beta^{2}+\eta^{2}\right)}\right] \\
& -\lambda\left(1-e^{-\beta h}\right)\left[\frac{1}{2} E\left[C^{2}-C\right] \mu^{2} \times \frac{1}{\beta\left(\beta^{2}+\eta^{2}\right)}\right] e^{-\beta(k-1) h}
\end{aligned}
$$

253 The target function of minimization is given by equation (13) (Alcocer 2007):

$$
Z=\left[\left(\frac{F_{1}(\xi)}{F^{\prime}{ }_{1}}-1\right)^{2}+\left(\frac{F_{2}(\xi)}{F^{\prime} 2}-1\right)+. .+\left(\frac{F_{n}(\xi)}{F_{n}^{\prime}}-1\right)^{2}\right]
$$

254 Where $F^{\prime}{ }_{1}, F^{\prime}{ }_{2} \ldots F_{n}^{\prime}$ are the observed moments, $i$.e. average, variance and covariance. 255 On the other hand $F_{1}, F_{2} \ldots F_{n}$ are the theoretical moments that are sought to find the necessary theoretical statistical parameters $\left\{\lambda, x, \mu_{c}, \mu_{x}, \eta, \beta\right\}$ for their introduction in a

257

computational model of synthetic series; In this study, Neyman Scott Rectangular Pulse was made using the model developed by Camici et al. (2011).

\subsection{Simultaneity Factor Method.}

The Qmp according to the methodology set out by (Miduvi 2011) was determined from equations (14) and (15):

$$
\begin{gathered}
\mathrm{Q}_{\mathrm{mp}}=\mathrm{K}_{\mathrm{s}} \sum \mathrm{qi} \\
\mathrm{K}_{\mathrm{s}}=\frac{1}{\sqrt{\mathrm{n}-1}}+\mathrm{F}(0.04+0.04 \log (\log (\mathrm{n}))
\end{gathered}
$$

Where $n$ is the total number of $s a, k s$ is the simultaneity coefficient, $q i$ is the unit flow of each $s a, F$ is a factor that takes the value of 4 for academic buildings.

\section{Results and Discussion}




\subsection{Hunter's probabilistic adaptation}

268 In order to determine a design flow rate under Hunter's methodology, it is necessary to

269

270

271

272

273

274

275

276

277 determine the duration of consumption $(t)$ and the frequency of use $(i)$. To obtain these values, the vertical double axis plots have been used, generated with daily information on each water meter.

As consumption is realized, the pressure in the system decreases; having a consumption variation in the pressure and flow in time, the values of $i$ and $t$ could be analyzed, as hydrograph, for each peak period $h$. This was carefully done with analysis of the database generated from the logs.

With the values of $i$ and $t$, the probability, $p$, described by equation (4) was determined. Authors such as Rojas et al. (2017) and Cortés (2008) mention that, in order to determine the daily $p$-value, only the values of $i$ and $t$ in morning and night peak flows should be determined. Since the variation in consumption in the academic facilities studied has shown that peak flow rates can occur at different points of the day, several values of $i$ and $t$ were determined, for each day in analysis.

Periods of maximum consumption $h$, identified daily, don't show patterns of influence in common peak hours (morning and night), their appearance doesn't appear to have a pattern of deterministic behavior, as they appear at any time of the day when the population of the academic facilities resides in it. Therefore, only 2 daily values of $p$ shouldn't be determined, there should be as much as possible values of $i, t$ and therefore $p$.

Having in mind the unforeseeable nature of the method, having multiple data describing the phenomenon helps the discrete random variable $n$ applied in equations (2) and (3) as a distribution function, you should generate a probability value that ensures the occurrence of a given concurrency event (Mazumdar et al. 2013). 
292 For the case in Figure 1, $22 t$-values and $22 i$-values were determined, the average of the 293 values were applied in equation (1), i.e. a daily $p$-value was obtained.

294

295

296

297

298

299

300

301

302

303

304

305

306

307

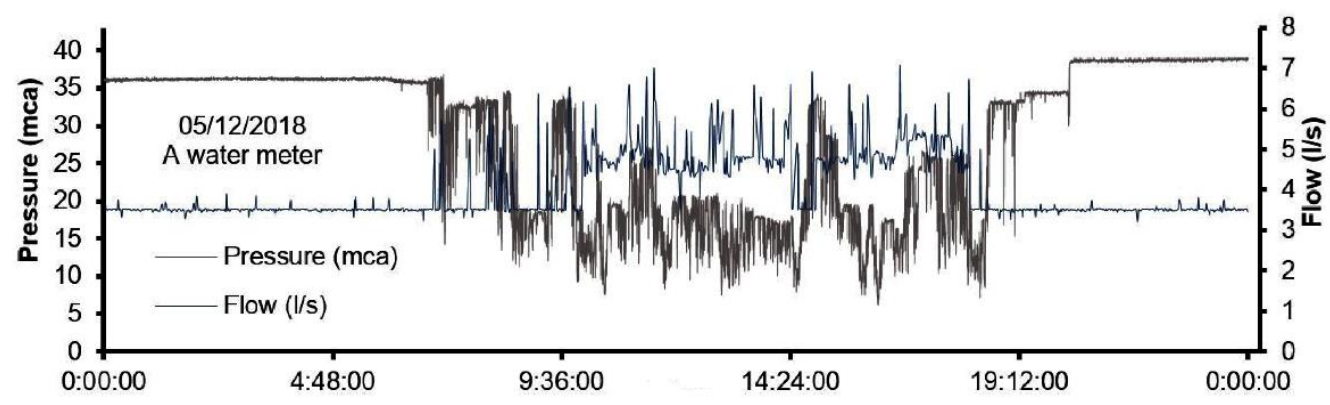

Figure 1. Pressure and flow variation over time, A water meter 05/12/2018.

The daily $n$-values obtained were averaged, generalizing a single probability of discharge value per water meter.

The $n$-value of each water meter was applied in equations (2) and (3) using different $m$ values until the condition described by the expression (5) was reached, that is, until $m$ of $n$ appliances operate $99 \%$ of the time, as suggested by Cortés (2008). Ordered pairs of $n$ and $m$ were generated for each building.

For the graph describing the $Q m p$ according to the number of sanitary appliances, a weighted flow for each building studied was determined, as detailed in Table 1. The unit flow for each $s a$ was obtained from NHE 2011 (Miduvi 2011).

\begin{tabular}{llllllllllll}
\hline $\begin{array}{l}\text { Sanitary } \\
\text { Appliances }\end{array}$ & $\mathbf{A}$ & $\begin{array}{l}\text { Q } \\
\text { Weigh } \\
\text { ted A }\end{array}$ & $\mathbf{B}$ & $\begin{array}{l}\text { Q } \\
\text { Weigh } \\
\text { ted B }\end{array}$ & $\begin{array}{c}\text { C } \\
\text { Weight }\end{array}$ & $\begin{array}{l}\text { Q } \\
\text { ed C }\end{array}$ & $\begin{array}{l}\text { Q } \\
\text { Weight } \\
\text { ed D }\end{array}$ & E & $\begin{array}{l}\text { Q } \\
\text { Weight } \\
\text { ed E }\end{array}$ & Q Unit (1/s) \\
\hline Water closet & 22 & 0.042 & 30 & 0.047 & 6 & 0.031 & 16 & 0.042 & 12 & 0.035 & 0.1 \\
Wash basin & 16 & 0.030 & 18 & 0.028 & 4 & 0.021 & 8 & 0.021 & 8 & 0.023 & 0.1 \\
Urinal & 12 & 0.034 & 12 & 0.028 & 3 & 0.023 & 4 & 0.015 & 6 & 0.026 & 0.15 \\
Sink & 2 & 0.007 & 3 & 0.009 & 6 & 0.063 & 10 & 0.052 & 8 & 0.047 & 0.2 \\
Total & 52 & 0.115 & 63 & 0.114 & 19 & 0.139 & 16 & 0.042 & 34 & 0.035 & - \\
\hline \multicolumn{1}{c}{308} & & & & & & & & & & &
\end{tabular}



of $n$ appliances operating simultaneously (ordered pairs), which is shown in Figure 2 (a).

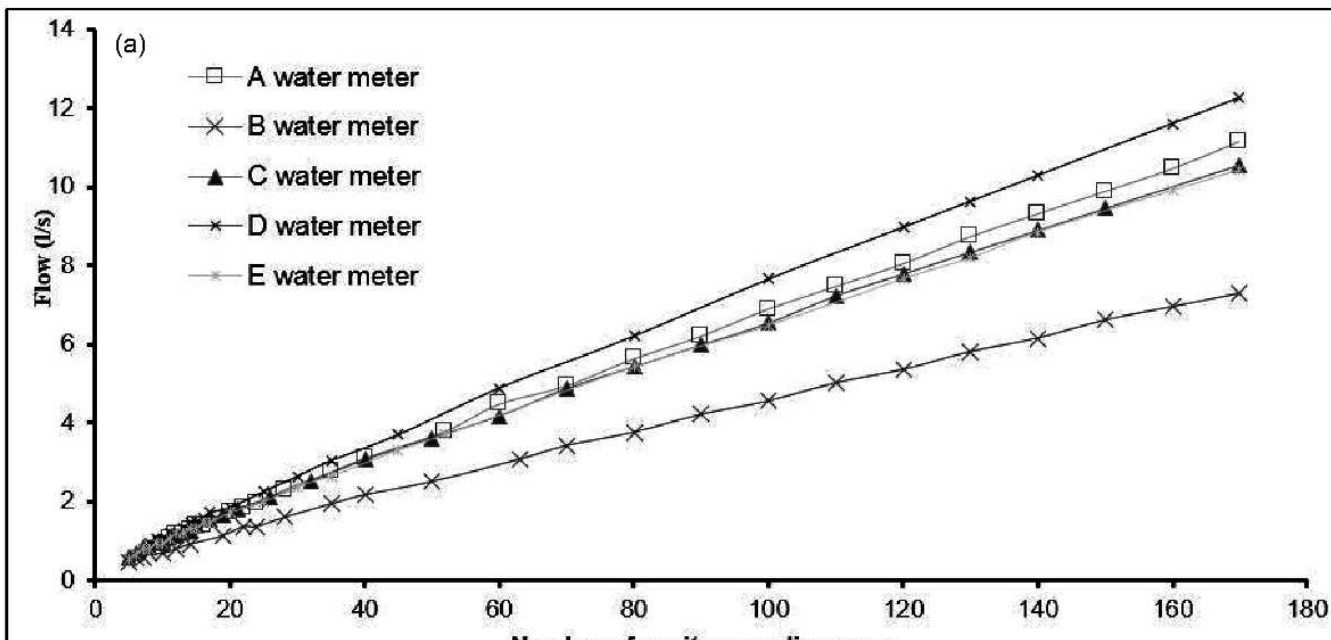

Number of sanitary appliances $\mathbf{n}$

Figure 2. (a) Flow based on the total number of $s a$. (b) Flow based on discharge units.

To plot consumption based on source units, the highest consumption for individual flow appliance was assigned a factor of 10, as suggested by Cortés (2008) and Hunter (1940). Considering the flow of each existing appliance, equation (6) was used to obtain the different source units per sanitary appliance.

318 Since the water consumption is based on several types of appliances, a total value $f$ was 319 determined based on the total $n$ of each building, as shown in Table 2. Considering the correspondence between $n$ and $f$ for each building, the values of $f$ were determined for 

discharge units. See result in Figure 3.

Table 2. Weighted supply units per water meters.

\begin{tabular}{llllllllllll}
\hline Water meter & & A & \multicolumn{3}{c}{ B } & C & \multicolumn{3}{c}{ D } & E \\
\hline $\begin{array}{l}\text { Sanitary } \\
\text { appliance }\end{array}$ & $\begin{array}{l}\text { Supply units } \\
\boldsymbol{f} \text { calculated }\end{array}$ & $\mathbf{s a}$ & $\boldsymbol{f}$ total & $\mathbf{s a}$ & $\boldsymbol{f}$ total & $\mathbf{s a}$ & $\boldsymbol{f}$ total & $\mathbf{s a}$ & $\boldsymbol{f}$ total & $\mathbf{s a}$ & $\boldsymbol{f}$ total \\
Water closet & 5 & 22 & 110 & 30 & 150 & 6 & 30 & 16 & 80 & 12 & 60 \\
Wash basin & 5 & 16 & 80 & 18 & 90 & 4 & 20 & 8 & 40 & 8 & 40 \\
Urinal & 7.5 & 12 & 90 & 12 & 90 & 3 & 22.5 & 4 & 30 & 6 & 45 \\
Sink & 10 & 2 & 20 & 3 & 30 & 6 & 60 & 10 & 100 & 8 & 80 \\
Total & & 52 & 300 & 63 & 360 & 63 & 132.5 & 38 & 250 & 34 & 225 \\
\hline
\end{tabular}

326

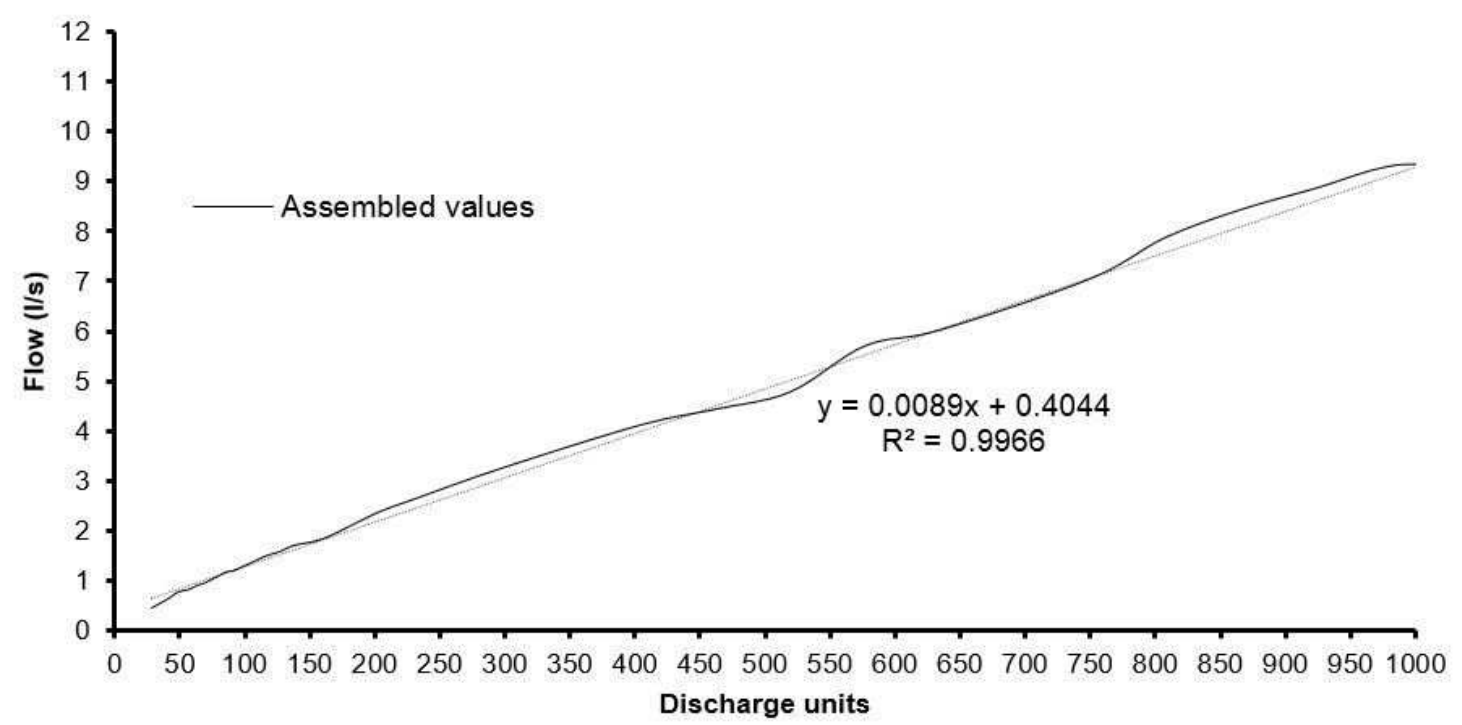

327

Figure 3. Assembled curve expense based on discharge units.

\subsection{NSRPM synthetic series}

331 From the flow records, a database was generated from which, independently on each

332 water meter, a curve was assembled for analysis, and following what is set by Alcocer

333 (2007), the average time between two events $\lambda^{-1}$, the average time between each

334 individual pulse and the event source $\beta^{-1}$, the average pulse duration $n^{-1}$, the average 
335 intensity (flow) of the pulses $u_{x}$ and the aggregation/disaggregation interval analyzed (1

336 minute) $h$ were determined.

337 From these, the variables of average, variance and covariance of each of the assembled

338 series were determined, in order to determine by minimizing the target function, the

339 theoretical moments, and with these, use the Model of Camici et al. (2011) for the

340 generation of the synthetic series. Due to the stochastic nature of the model, several

341 simulations with different random seeds were developed in order to reduce uncertainty

342 within the NSRPM. It was considered as optimal that random seed that generates a flow

343 equal to or greater than that observed in the assembled series.

344 The 5 assembled series, one for each gauge, represent an average value of the recorded

345 flow rate, from these, 5 synthetic series were developed that are observed in Figure 4.

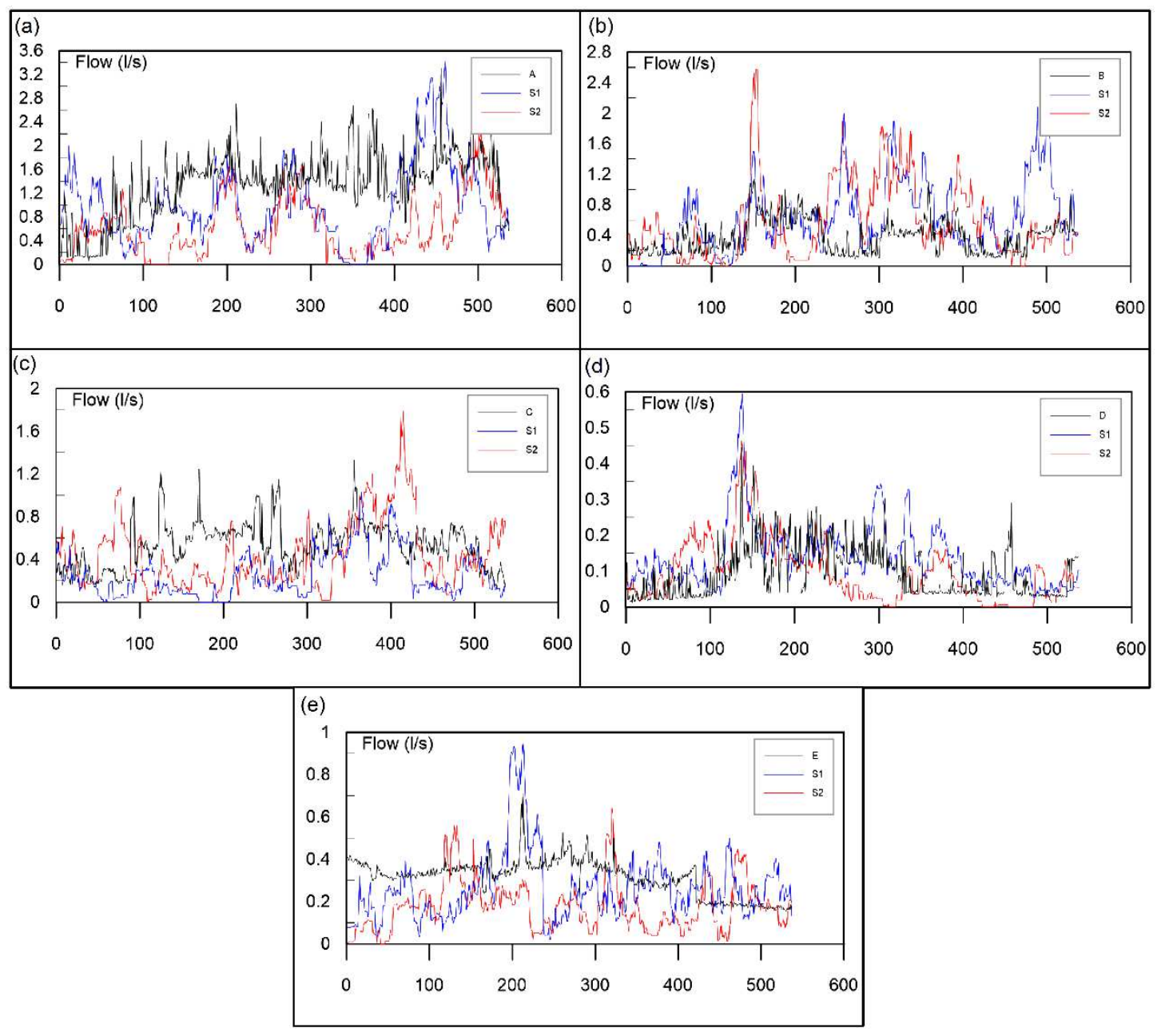


347 Figure 4. NSRPM synthetic series. (a) A water meter. (b) B water meter. (c) C water 348 meter. (d) D water meter. (e) E water meter.

\subsection{Comparative analysis}

351 Flow values obtained through NHE 2011 are lower than the observed maximum flow 352 rates, on average $31.35 \%$. D and $\mathrm{E}$ water meters are highlighted, which are lower by a percentage near 10\%. NHE 2011 methodology involves the sum of $s a$ flows affected by a simultaneity factor, in meters D and E, there are several $s a$ with a flow of $0.2 \mathrm{l} / \mathrm{s}$, this being a relatively a high flow; the sum of these flows affected by a simultaneity factor resulted in a $Q m p$ close to the observed maximum. The values of $\mathrm{A}, \mathrm{B}$ and $\mathrm{C}$ water meters aren't close to the observed maximum because the $s a$ mostly have unit flows close to 0.1 $1 / \mathrm{s}$.

The adaptation developed in this document, is very assertively close to the observed flow values, being the case of the $\mathrm{C}$ water meter $11.6 \%$ lower, and for the $\mathrm{D}$ water meter $20.0 \%$ higher, on average is approximately $20.6 \%$. As there is a higher population on A, B and $\mathrm{C}$ water meters, the probabilities of simultaneous use are higher than those of D and $\mathrm{E}$ water meters, so the modified Hunter curve tends to adjust to an average trend, giving acceptable results.

In the case of WDC, the estimated flow rates differ in a very wide range, relative to the observed maximum, this is because the model was proposed for home residences, without floating population, so the probability of simultaneous use of several $s a$ is lower, consequently the estimated $Q m p$ is also $81.5 \%$. The model is useful and involves an efficient and rational use of water, however, for academic facilities with high floating population, it is not applicable. 
371 NSRPM, provides values lower than the maximums, in a very wide range; as mentioned

372 in previous sections, because consumption is made when the floating population resides

373 within the academic facilities, there is no common peak period of consumption, and this

374 can occur at different times of the day; for this reason averaging consumption can lead to

375 underestimations in the series and synthetic series presenting low values. For $\mathrm{C}$ water

376 meter, the obtained value is less than $1.1 \%$, relative to the observed, although on average

377 the values are $38.42 \%$ lower. Considering this, it is optimal to generate several

378 simulations and choose one whose random seed produces a relatively higher flow,

379 reducing the uncertainty of the method and bringing the value closer to the maximum

380 observed.

381 Authors such as Cortés (2008), García et al. (2004), and Rojas et al. (2017) point out that

382 for residential consumption, flow and/or pressure values must be recorded in morning and

383 night peak times, with those outside these hours being disposable. The time series of

384 consumption generated in this study showed that the maximum consumption in academic

385 buildings can occur at different times of the day, provided that the population resides in

386 the building, so no data could be ruled out from this analysis.

387 Alcocer (2007), Blokker et al. (2010), and Gargano et al. (2016) established a short registration frequency $(1 \mathrm{~Hz})$, during several days of monitoring for the characterization of residential consumption in their studies. This study had a recording frequency of $(1 / 60$ $\mathrm{Hz}$ ) for flow rates; having in mind that consumption occurred in educational facilities, the duration of hydrograph or pulses and the time between events had long intervals, so no lower frequency of registration was necessary. The results generated by Cortés (2008), largely resemble the getable curve depending on the appliance units or consumption generated in this study. 
NHE 2011 does not consider the resident population of a building, as well as its characteristics (fixed or floating); the likelihood of simultaneous use increases if resident population is higher, Hunter implicitly considers it as its consumption curve is given to reason of duration and frequencies of consumption, as well as the time between events.

\section{Conclusions}

The research had an exploratory character, a theoretical value and a methodological utility was developed for subsequent studies that expand the line of research of water consumption on educational buildings. Applied methodology can be transferred to other building type such as residential, commercial or any other with floating population. It's a non-experimental design.

No patterns of impact are observed in common peak hours (morning and night) for periods of maximum consumption $h$, its appearance does not have a deterministic pattern or predictable behavior; therefore, several daily values of $n$ must be determined, to make an adaptation of the Hunter's Method in buildings of academic facilities.

The modification to the proposed Hunter's Method in this study is the most recommended for water supply systems in educational buildings whose population ranges from 220 to 1514 students, and whose inlet diameters range from $12.5 \mathrm{~mm}$ to $25.4 \mathrm{~mm}$.

The NHE 2011 method was valid for populations ranging from 220 to 360 students, whose inlet diameters range from $12.5 \mathrm{~mm}$ to $20.0 \mathrm{~mm}$.

The NSRPM method was excellent, with only a $1.1 \%$ percentage difference compared to the measured one, for a population of 312 students and with a rush diameter of $20.0 \mathrm{~mm}$. Its stochastic nature, allows to choose from several random seeds, those values that 
419 conform to the actual behavior of users. The model can provide an accurate flow estimation.

421 The use of the binomial probability function, from the disaggregation of time series, is a useful approach for adapting the Hunter's Method.

\section{Declarations}

425 Funding This research did not receive any specific grant from funding agencies in the public, commercial, or not-for-profit sectors.

Conflict of Interest The authors declare no conflict of interest.

Availability of data and material Some or all data and models that support the findings of this study are available from the corresponding author upon reasonable request (water use database, inputs for Hunter's adaptation, synthetic series).

Code availability Code used in this study is available from the corresponding author upon reasonable request

Ethics approval This article does not contain any studies with human participants or animals performed by any of the authors.

435 Consent to participate The authors declare that they have agreed to participate.

436 Consent for publication The authors give consent to publish.

\section{References}

Alcocer-Yamanaka VH, Tzatchkov V (2009) Estimación de parámetros del consumo instantáneo de agua potable de lecturas acumuladas. Ing Investig y Tecnol UNAM 10:237-246. https://doi.org/http://dx.doi.org/10.22201/fi.25940732e.2009.10n3.022 

water distribution networks using stochastic demand. Water Resour Manag 26:1779-1792. https://doi.org/10.1007/s11269-012-9979-2

Alcocer VH (2007) Flujo estocástico y transporte en redes de distribución de agua potable. Universidad Nacional Autónoma de México

Alvisi S, Franchini M, Marinelli A (2003) A stochastic model for representing drinking water demand at residential level. Water Resour Manag 17:197-222. https://doi.org/10.1023/A:1024100518186

Arreguín FI, Alcocer-Yamanaka VH, Hernández-Padrón DS (2010) Modelación de redes de agua potable con enfoques determinísticos y estocásticos. Tecnol y Ciencias del Agua 1:119-136

Blokker M, Vreeburg J, C van Dijk J (2010) Simulating Residential Water Demand with a Stochastic End-Use Model. J Water Resour Planin Manag 136:19-26

Buchberger S, Omaghomi T, Wolfe T, et al (2017) Peak water demand study. Probability estimates for efficient fixtures in single and multi-family residential buildings.

Buchberger SG, Li Z (2007) PRPsym : A Modeling System for Simulation of Stochastic Water Demands. World Environ Water Resour Congr 1-13

Camici S, Tarpanelli A, Brocca L, et al (2011) Design soil moisture estimation by comparing continuous and storm-based rainfall-runoff modeling. Water Resour Res 47:1-18. https://doi.org/10.1029/2010WR009298

Castro N, Garzón J, Ortiz R (2006a) Aplicación de los métodos para el cálculo de caudales máximos probables instantáneos, en edificaciones de diferente tipo. VI SEREA Semin Iberoam sobre Sist Abast Urbano Água João Pessoa (Brasil), 5 a 7 junho 2006 $1-14$ 
467 Castro N, Garzón J, Ortiz R (2006b) Adaptación del método de hunter para las condiciones locales en Colombia. VI SEREA - Semin Iberoam sobre Sist Abast Urbano Água João Pessoa (Brasil), 5 a 7 junho 2006 1-7

Cortés C (2008) Análisis del método de Hunter y actualización del método de cálculo para instalaciones hidráulicas en edificios. Dirección de Posgrado

García J, García R, Cabrera E, et al (2004) Stochastic Model to Evaluate Residential Water Demands. J Water Resour Planin Manag 130:386-394. https://doi.org/10.1061/(ASCE)0733-9496(2004)

KOBOLD MIK Medidor de Caudal Magnético- Inductivo Compacto

Manco D, Guerrero J, Ocampo A (2012) Eficiencia en el Consumo de Agua de Uso Residencial. Rev Ing Univ Medellín 11:23-38

Mazumdar A, Jaman H, Das S (2013) Modification of Hunter's Curve in the Perspective of Water Conservation. J pipeline Syst Eng Pract 5:1-9. 
https://doi.org/10.1061/(ASCE)PS.1949-1204.0000150.

490

491

492

493

494

495

496

497

498

499

500

501

502

503

504

505

506

507

Miduvi (2011) Norma ecuatoriana de la construcción Norma Hidrosanitaria NHE Agua. Quito

Omaghomi T, Buchberger S (2014) Estimating Water Demands in Buildings. Procedia Eng 89:1013-1022. https://doi.org/10.1016/j.proeng.2014.11.219

Omaghomi T, Buchberger S, Cole D, et al (2020) Probability of Water Fixture Use during Peak Hour in Residential Buildings. J Water Resour Plan Manag 146:1-10. https://doi.org/10.1061/(ASCE)WR.1943-5452.0001207

Omega Eng Omega OM-PL Series Data Logger Interface

Polebitski AS, Palmer RN (2010) Seasonal Residential Water Demand Forecasting for Census Tracts. J Water Resour Planin Manag 136:27-36

Rojas DC, Aldana J, Huertas EZ (2017) Cálculo de unidades de consumo a través de caudales máximos instantáneos medidos en cuatro zonas de servicio de la ciudad de Bogotá D . C . Calculation of consumption units through instantaneous maximum flows measured in four service areas of the city of. Av Investig en Ing 14:123-132

Soriano A, Pancorbo F (2012) Suministro, distribución y evacuación interior de agua sanitaria., Primera. Marcombo SA, Barcelona España

Wong LT, Mui KW (2006) Evaluation of 'Discharge Units' for Domestic Washrooms in Hong Kong. Archit Sci Rev 49:418-421. https://doi.org/10.3763/asre.2006.4954 
Figures

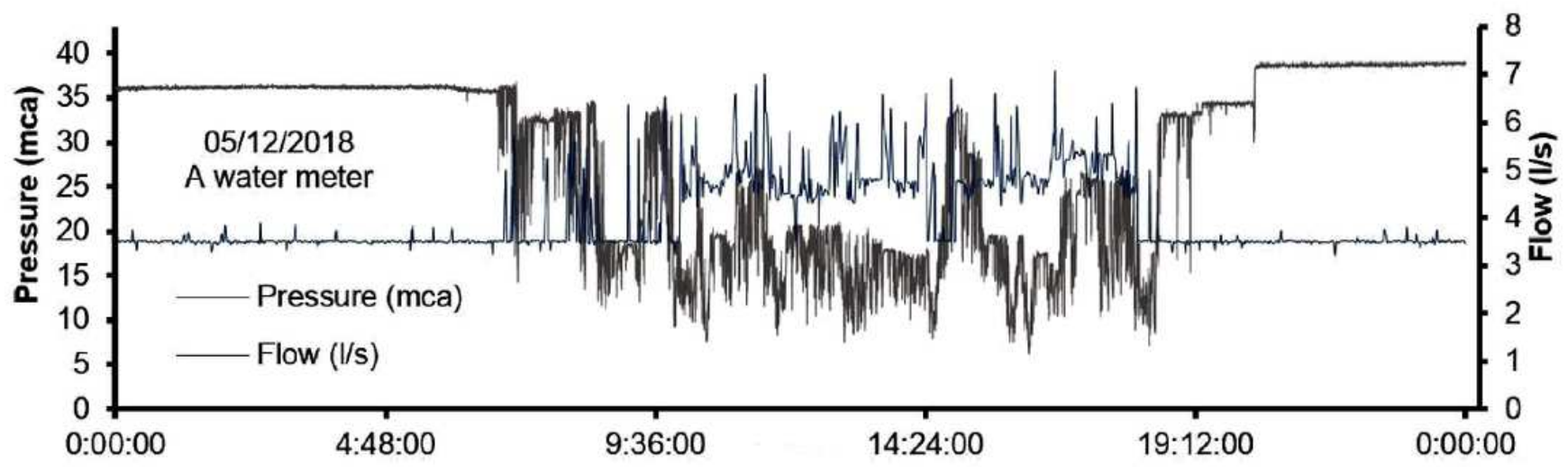

Figure 1

Pressure and flow variation over time, A water meter 05/12/2018. 


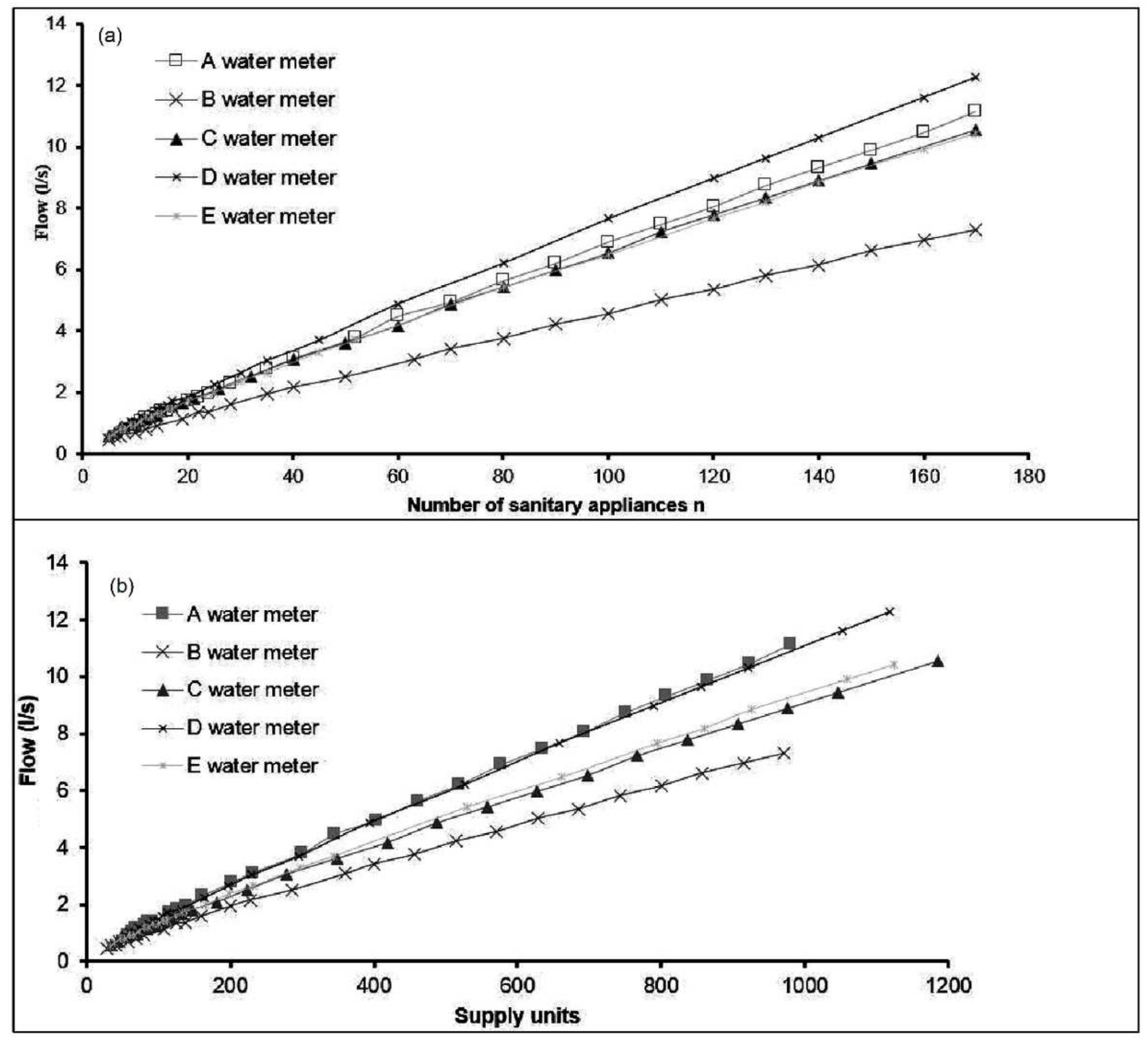

Figure 2

(a) Flow based on the total number of sa. (b) Flow based on discharge units. 


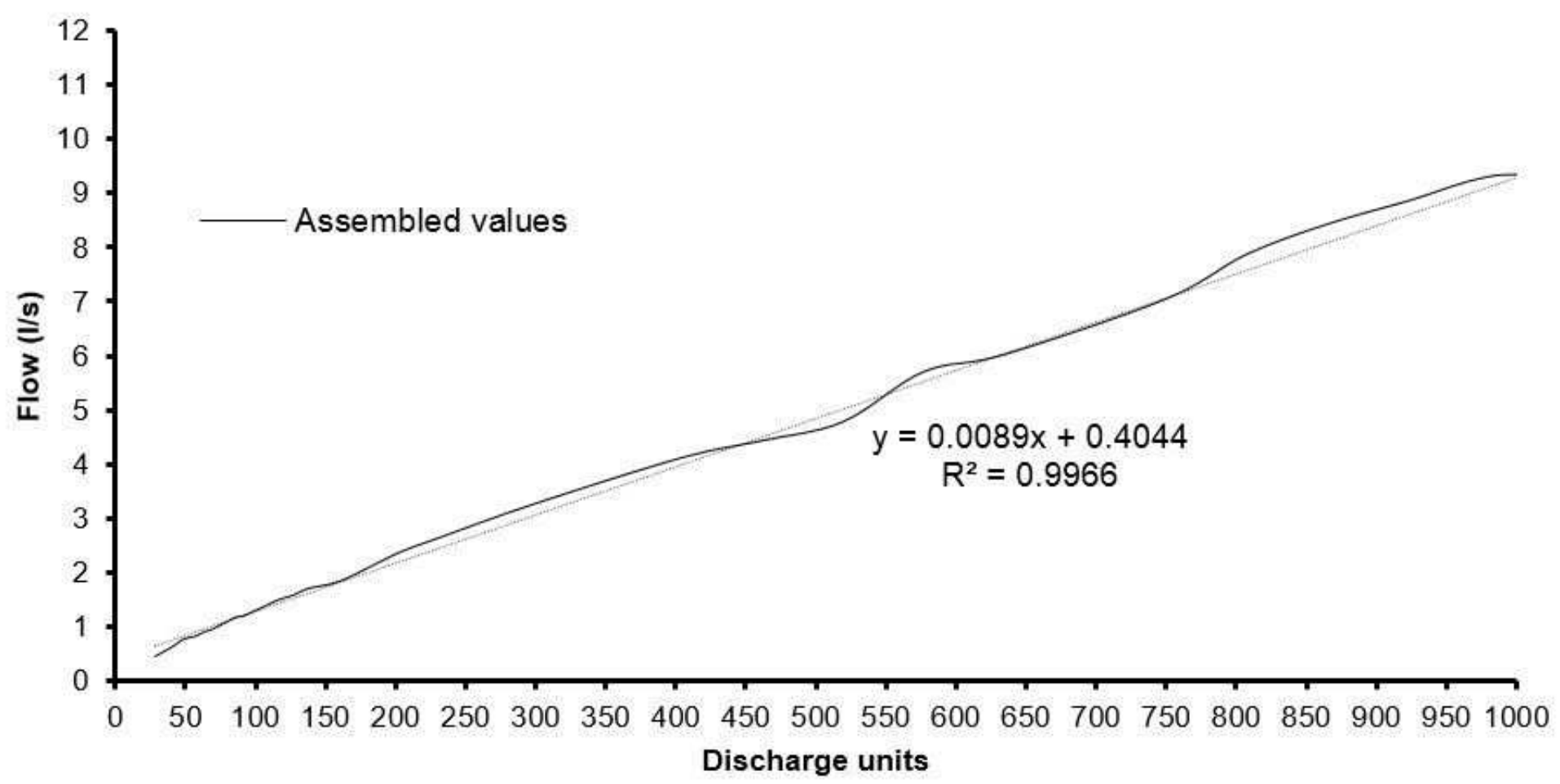

Figure 3

Assembled curve expense based on discharge units. 


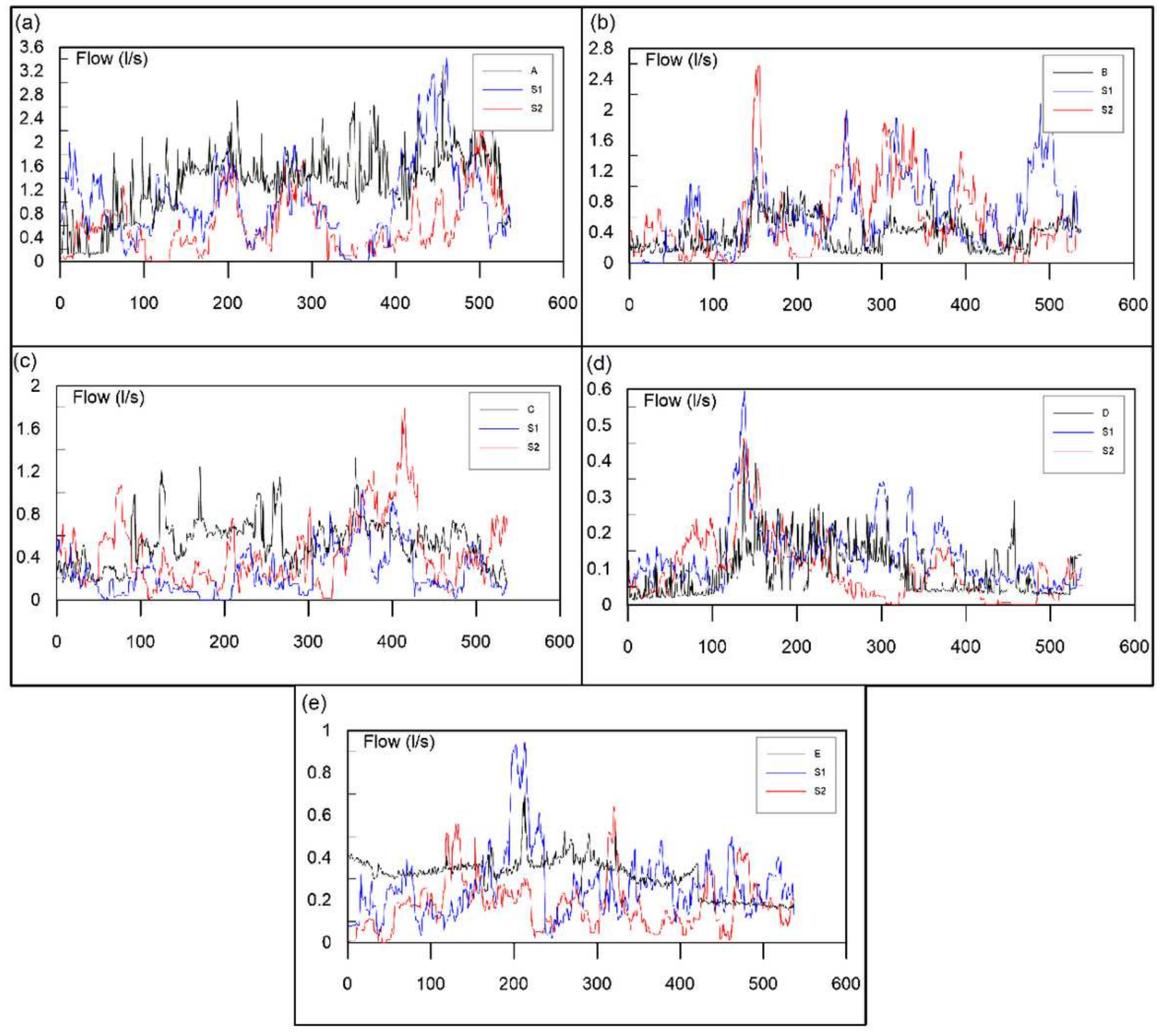

Figure 4

NSRPM synthetic series. (a) A water meter. (b) B water meter. (c) C water meter. (d) D water meter. (e) E water meter 